\title{
COMPARATIVE STUDY BETWEEN BUPIVACAINE INFILTRATION, TOPICAL LIDOCAINE AND INTRA VENOUS PARACETAMOL IN MANAGEMENT OF POST-TONSILLECTOMY PAIN IN CHILDREN
}

\author{
By \\ Mohammed Ahmed El-Sharkawy and Yusry A. El-Salam Kandil* \\ Departments of Otorhinolaryngology and Anesthesiology \& Intensive care*, Faculty of \\ Medicine, Al-Azhar university (Cairo \&Damietta) \\ E-mail: sharkosh@gmail.com - yousrykandil@yahoo.com
}

\begin{abstract}
Background: Tonsillectomy operation is a one of the most commonly performed procedures in pediatric population. Post-operative pain control in those children is very important.

Objective: To compare the efficacy of bupivacaine infiltration in gloss-tonsillar sulcus, applying a gauze soaked in lidocaine (10\%) in tonsillar bed and intravenous injection of paracetamol in management of posttonsillectomy pain in children.

Patients and Methods: Sixty kids of both sexes were included in this clinical randomized study, aged from 5to 12 years undergoing tonsillectomy at Al-Azhar university hospitals between January 2019 and December 2019. They were randomly allocated into three equal groups: Group (A) underwent pre-operative single-point superficial infiltration of a dose of $1 \mathrm{mg} / \mathrm{kg}$ bupivacaine $(0.5 \%)$ in glosso-tonsillar sulcus, Group (B) underwent post-operative application of a soaked piece of gauze in lidocaine (10\%) in the tonsillar bed, and Group (C) underwent preoperative intravenous infusion of $10 \mathrm{mg} / \mathrm{ml}$ paracetamol solution. They were followed up to assess the effectiveness and safety of which medication in pain management post tonsillectomy.
\end{abstract}

Results: There was no statistically significant difference between pain scores in the three groups after 30 minutes, 2 and 6 hours. There was a statistically significant difference between pain scores in the three groups after 12, 18 and 24 hours respectively. Pair-wise comparisons between the groups revealed that Group B showed the statistically significantly highest mean pain score. There was no statistically significant difference between Group A and Group C; both showed the statistically significantly lowest mean pain scores.

Conclusion: The glossopharyngeal nerve block with plain bupivacaine $(0.5 \%)$ in glooso-tonsillar sulcus is a safe, effective \&easily applicable method for post-tonsillectomy pain management and has a significant prolonged duration of analgesia in comparison to topical lidocaine and Intravenous paracetamol. However, paracetamol injection was more effective than lidocaine infiltration.

Keywords: Tonsillectomy, pain, bupivacaine, lidocaine, paracetamol.

\section{INTRODUCTION}

Post-operative pain management in children undergoing tonsillectomy is a very important topic. An adequate postoperative analgesia is essential after tonsillectomy, as pain after tonsillectomy impairs swallowing with a risk of dehydration, infection and secondary 
hemorrhage, and may interfere with speedy recovery and smooth convalescence. This pain has the maximum intensity immediately after operation and in the first $24 \mathrm{hrs}$ (Ahmed and Omara, 2019).

There is a wide range of analgesic methods used for postoperative pain control in children undergoing elective tonsillectomy, and there are many cases in which the postoperative analgesic modalities have not been fully successful to treat pain effectively. Systemic analgesics and opioids provide pain relief, but also produce undesirable side effects. The alternative is to use a local anesthetic agent along with general anesthesia. Infiltration of local anesthetic agent like bupivacaine and lignocaine, have been carried out either pre or post operatively in the tonsillar fossa with conflicting results (Debasish et al., 2018). Peritonsillar infiltration of different types of drugs in children undergoing adenotonsillectomy has been cited many times during the past years, using local anesthetics, opioids (Akkaya et al., 2009), corticosteroids (Mohamed et al., 2009), ketamine (Inanglou et al., 2009), gabapentin (Jeon et al., 2009) and even non-pharmacologic interventions as adjuvant local analgesic compounds (Parker et al., 2009).

Hemorrhage, airway obstruction due to edema are the most serious complications observed post operatively after tonsillectomy. Pain is the most common complaint in early post-operative period. Pain causes anxiety and fear of swallowing with individual variations and predisposes to delayed food intake, limits respiratory effort with increased chance of pulmonary complications and lengthens the stay in hospital (Yucel and Ozdogan, 2020).

The inhibition of central sensitization by local or systemic drugs is known as pre-emptive analgesia that helps to control postoperative pain. Pre-emptive analgesia has been tried with opioids, steroids, and NSAIDS as well as local anesthetics sprays and infiltration in tonsillar fossa (Debasish et al., 2018).

The present work aimed to compare the efficacy of bupivacaine infiltration in glosso-tonsillar sulcus, spraying of lidocaine $(10 \%)$ in tonsillar bed, and intravenous injection of paracetamol in management of post-operative pain in children undergoing tonsillectomy operation.

\section{PATIENTS AND METHODS}

This clinical randomized study was carried out after local ethics committee approval and written informed consents from the parents of 60 children undergoing tonsillectomy at Al-Azhar University Hospitals between January 2019 and December 2019.

\section{Inclusion criteria:}

Age from 5-12 years and suffering from either recurrent episodes of tonsillitis $\geq 3$ episodes per year in the past year, $\geq 5$ episodes in the preceding 2 years or $\geq 7$ episodes in the preceding 3 years.

\section{Exclusion criteria:}

Children with diabetes mellitus, cardiac, renal or liver diseases, obstructive sleep apnea syndrome, blood disease or bleeding tendency, those suspected for having hypersensitivity to the used medication, and those undergoing 
simultaneous procedure in the field of surgery like adenoidectomy or tongue tie.

All patients were subjected to complete blood count (CBC), partial thromboplastin time (PTT), prothrombin time (PT), prothrombin concentration (PC) and erythrocyte sedimentation rate (ESR).

Patients were randomly allocated into 3 equal groups: Group (A) underwent preoperative infiltration of bupivacaine, Group (B) underwent post-operative application of lidocaine, and Group (C) underwent preoperative intravenous paracetamol infusion.

The analgesia was differently applied according to the group of the patient: Group (A) underwent single-point superficial infiltration (in a depth of about $3 \mathrm{~mm}$ ) of a dose of $1 \mathrm{mg} / \mathrm{kg}$ bupivacaine $(0.5 \%)$ in glosso-tonsillar sulcus 5 minutes before tonsillectomy, Group underwent application of a soaked piece of gauze (measuring about $3 \times 3 \mathrm{~cm}$ ) in 2 $\mathrm{ml}$ of lidocaine $(10 \%)$ in the tonsillar bed for 3 minutes after tonsillectomy, and Group (C) underwent preoperative intravenous infusion of $(10 \mathrm{mg} / \mathrm{ml})$ paracetamol solution in a dose of $15 \mathrm{mg}$ $/ \mathrm{kg}$ over at least 15 minutes, and 10 minutes prior to the procedure.

Patients were assessed for postoperative pain $30 \mathrm{~min}, 2 \mathrm{hrs}, 6 \mathrm{hrs}, 12 \mathrm{hrs}$, $18 \mathrm{hrs}$. and $24 \mathrm{hrs}$. using facial expression (Wong-Baker scale), and dysphagia in the recovery room.

The time for first request of rescue analgesia was recorded, representing the time interval between the end of the surgery and the first request of rescue analgesia. If there was any pain score more than 3 of 10 in any of the assessments, the patient was treated with incremental rectal doses of rectal paracetamol $(10 \mathrm{mg} / \mathrm{kg})$ until the VAS score was 3. If pain persisted despite administering rectal paracetamol, intravenous pethidine with a dose of 0.4 $\mathrm{mg} / \mathrm{kg}$ was administered. The whole time of surgery was recorded. The incidence of perioperative complications such as postoperative nausea and vomiting, choking, toxicity of local anesthetic, dry mouth, nasal obstruction, hoarseness of voice or foreign body sensation in the throat, dyspnea, bradycardia, were also assessed. The children were discharged from the hospital after at least 24 hours if there was no bleeding, nausea or vomiting and they were able to swallow clear fluids and their pain score was less than three.

\section{Statistical Analysis:}

All of the numerical data were explored for normality through checking the distribution of data and by using tests of normality (Kolmogorov-Smirnov and Shapiro-Wilk tests). All data showed normal (parametric) distribution except for pain (VAS) scores data which showed non-normal (non-parametric) distribution. Data were presented in the form of mean and standard deviation (SD) values. For parametric data, one-way ANOVA test was used for comparisons between the groups. When ANOVA test was significant, Bonferroni's post-hoc test was used for pair-wise comparisons. For nonparametric data, Kruskal-Wallis test was used to compare between the three groups. Also, Friedman's test was used for studying the changes by time within every group. For pair-wise comparisons, Dunn's test was used. On the other hand, qualitative data were presented as 
frequencies and percentages. Chi-square test and Fisher's exact test were used for comparisons between the groups. The level of significance was at $\mathrm{P} \leq 0.05$.
Statistical analysis was done with IBM SPSS program for statistics for Windows, Version 23.0. Armonk, NY: IBM Corp.

\section{RESULTS}

The present study was conducted on 60 cases with equal number of cases i.e. 20 cases in each of the three groups. As regard age and sex, there was no statistically significant difference between the studied groups $(\mathrm{p}<0.05)$ (Table 1). As regard heart rate, respiratory rate and oxygen saturation, there was no statistically significant difference in all of them $(\mathrm{P}$-value $>0.05$, Effect size $=0.666)$, $(\mathrm{P}$-value $>0.05$, Effect size $=0.507),(\mathrm{P}-$ value $>0.05$, Effect size $=0.860$ ) respectively (Table 2 ).

Table (1): Mean, standard deviation (SD), frequencies (n) and results of one-way ANOVA test and Chi-square test for comparisons of demographic data in the three groups

\begin{tabular}{|c|c|c|c|c|c|}
\hline \multicolumn{2}{|c|}{ Groups } & $\begin{array}{c}\text { Group A } \\
\text { Parameters }\end{array}$ & $\begin{array}{c}\text { Group B } \\
(\mathbf{N}=\mathbf{2 0})\end{array}$ & $\begin{array}{c}\text { Group C } \\
(\mathbf{N}=\mathbf{2 0})\end{array}$ & \multirow{2}{*}{-value } \\
\hline \multicolumn{2}{|c|}{ Age (mean \pm SD) } & $8.0 \pm 3.7$ & $8.6 \pm 3.8$ & $8.0 \pm 2.6$ & $>0.05$ \\
\hline \multirow{2}{*}{ Sex } & Male & 12 & 11 & 13 & \multirow{2}{*}{$>0.05$} \\
\cline { 2 - 6 } & Female & 8 & 9 & 7 & \\
\hline
\end{tabular}

Table (2): Mean, standard deviation (SD), frequencies (n) and results of one-way ANOVA test for comparisons of operative data in the three groups

\begin{tabular}{|c|c|c|c|c|c|}
\hline Groups & $\begin{array}{c}\text { Group A } \\
(\mathbf{N = 2 0})\end{array}$ & $\begin{array}{c}\text { Group B } \\
(\mathbf{N}=\mathbf{2 0})\end{array}$ & $\begin{array}{c}\text { Group C } \\
(\mathbf{N}=20)\end{array}$ & $\begin{array}{c}\boldsymbol{P} \text { - } \\
\text { value }\end{array}$ & $\begin{array}{c}\text { Effect } \\
\text { size }\end{array}$ \\
\hline HR & $92 \pm 3.2$ & $93 \pm 2.8$ & $93 \pm 5.2$ & $>0.05$ & $f=0.666$ \\
\hline RR & $20 \pm 2.4$ & $19 \pm 6.3$ & $20 \pm 5.7$ & $>0.05$ & $f=0.507$ \\
\hline $\begin{array}{c}\text { Oxygen saturation } \\
(\boldsymbol{\%})\end{array}$ & $99 \pm 5.2$ & $100 \pm 0$ & $100 \pm 0$ & $>0.05$ & $f=0.860$ \\
\hline
\end{tabular}

Also, there was no statistically significant difference as regard duration of anesthesia and duration of the surgical procedure in which ( $\mathrm{p}$ - value $=0.1430$, effect size $=1.419)$, $(\mathrm{p}$ - value $=.084$, effect size $=1.608)$, respectively. According to the time for the first request of rescue analgesia, there was statistically significant ( $\mathrm{p}$-value $<0.001$ ) prolonged duration in group $\mathrm{A}$ in which (duration $=322 \pm 6.37$ ), but in Group $\mathrm{C}$ (duration= $281 \pm 5.8$ ), and Group C revealed the lowest time for first rescue analgesia $($ duration $=236 \pm 6.5)$ (Table 3). 
Table (3): Mean, standard deviation (SD), frequencies (n) and results of one-way ANOVA test for comparisons of operative data in the three groups

\begin{tabular}{|c|c|c|c|c|c|}
\hline $\begin{array}{ll}\text { Parameters } & \text { Groups } \\
\end{array}$ & $\begin{array}{c}\text { Group A } \\
(\mathbf{N}=\mathbf{2 0})\end{array}$ & $\begin{array}{c}\text { Group B } \\
(\mathbf{N}=\mathbf{2 0})\end{array}$ & $\begin{array}{c}\text { Group C } \\
(\mathbf{N}=20)\end{array}$ & $P$-value & Effect size \\
\hline $\begin{array}{l}\text { Duration of anesthesia } \\
(\text { min })(\text { mean } \pm \text { SD })\end{array}$ & $40.33 \pm 3.84$ & $39.13 \pm 2.65$ & $41.02 \pm 2.34$ & $>0.05$ & $f=1.419$ \\
\hline $\begin{array}{l}\text { Duration of } \\
\text { tonsillectomy }(\mathrm{min}) \\
(\text { mean } \pm \text { SD) }\end{array}$ & $21.27 \pm 4.06$ & $20.3 \pm 4.33$ & $23.16 \pm 3.72$ & $>0.05$ & $f=1.608$ \\
\hline $\begin{array}{l}\text { Time to request of } \\
\text { analgesic (min) (mean } \\
\pm \text { SD) }\end{array}$ & $322 \pm 6.37$ & $236 \pm 6.5$ & $281 \pm 5.8$ & $<0.001 *$ & $f=30.874$ \\
\hline $\begin{array}{l}\text { No. of children } \\
\text { receiving analgesics in } \\
\text { 1st } 24 \text { hrs. }\end{array}$ & 1 & 5 & 4 & $>0.05$ & $v=0.228$ \\
\hline
\end{tabular}

There was no statistically significant difference in pain scores between three groups after 30 minutes, 2 and 6 hours in which $(\mathrm{P}$-value $=0.184$, Effect size $=$ $0.024)$, $($ P-value $=0.132$, Effect size $=$ $0.036)$ and $(\mathrm{P}$-value $=0.165$, Effect size $=$ 0.028 ), respectively. But there was a statistically significant difference in pain scores between three groups after 12, 18 and 24 hours in which (P-value $<0.001$, Effect size $=0.574),(\mathrm{P}$-value $<0.001$, Effect size $=0.508)$ and $(\mathrm{P}$-value $<0.001$,
Effect size $=0.456$ ), respectively. Pairwise comparisons between the groups revealed that Group $B$ showed the statistically significantly highest ( $\mathrm{P}$-value $<0.001)$ mean pain score. While comparing group $\mathrm{A}$ and $\mathrm{C}$ there was increase in pain score in group $\mathrm{C}$ than group A but without a statistically significant difference and both showed the statistically significant lowest mean pain scores (Table 4).

Table (4): Mean \pm standard deviation (SD) and results of Kruskal-Wallis test for comparisons of pain (VAS) scores in the three groups and Friedman's test for the changes by time within each group

\begin{tabular}{|c|c|c|c|c|c|}
\hline $\begin{array}{c}\text { Groups } \\
\text { Parameters }\end{array}$ & & & & $P$-value & $\begin{array}{c}\text { Effect size } \\
\text { (Eta squared) }\end{array}$ \\
\hline $30 \mathrm{~min}$. & $2.2 \pm 0.52$ & $2.4 \pm 0.82$ & $2.2 \pm 048$ & $>0.05$ & 0.024 \\
\hline 2 hrs. & $2.25 \pm 0.55$ & $2.6 \pm 0.88$ & $2.35 \pm 0.59$ & $>0.05$ & 0.036 \\
\hline 6 hrs. & $2.55 \pm 0.76$ & $2.95 \pm 0.89$ & $2.85 \pm 0.67$ & $>0.05$ & 0.028 \\
\hline 12 hrs. & $2.65 \pm 0.75$ & $4.5 \pm 0.82$ & $2.75 \pm 0.79$ & $<0.001 *$ & 0.574 \\
\hline 18 hrs. & $2.9 \pm 0.85$ & $5.2 \pm 1.00$ & $3.05 \pm 0.94$ & $<0.001 *$ & 0.508 \\
\hline 24 hrs. & $3.15 \pm 0.99$ & $5.3 \pm 0.80$ & $3.7 \pm 1.13$ & $<0.001 *$ & 0.456 \\
\hline$P$-value & 0.062 & $<0.001^{*}$ & 0.052 & & \\
\hline Effect size (w) & 0.185 & 0.822 & 0.168 & & \\
\hline
\end{tabular}

There was no statistically significant difference between severity of dysphagia in the three groups $(\mathrm{P}$-value $=0.724$,
Effect size $=0.180)$ ) as showed in (Table 5). 
Table (5): Frequencies, percentages (\%) and results of Fisher's Exact test for comparison between severity of dysphagia in the three groups

\begin{tabular}{|c|c|c|c|c|c|}
\hline Gysphagia & $\begin{array}{c}\text { Group A } \\
(\mathbf{N}=\mathbf{2 0})\end{array}$ & $\begin{array}{c}\text { Group B } \\
(\mathbf{N = 2 0})\end{array}$ & $\begin{array}{c}\text { Group C } \\
(\mathbf{N}=\mathbf{2 0})\end{array}$ & $\begin{array}{c}\text { P- } \\
\text { value }\end{array}$ & $\begin{array}{c}\text { Effect } \\
\text { size (v) }\end{array}$ \\
\hline No & $18(90 \%)$ & $14(70 \%)$ & $16(80 \%)$ & & \\
\cline { 1 - 4 } Mild & $1(5 \%)$ & $2(10 \%)$ & $2(10 \%)$ & \multirow{2}{*}{$>0.05$} & \multirow{2}{*}{0.180} \\
\cline { 1 - 4 } Moderate & $1(5 \%)$ & $3(15 \%)$ & $2(10 \%)$ & & \\
\hline Severe & $0(0 \%)$ & $1(5 \%)$ & $0(0 \%)$ & \\
\cline { 1 - 3 }
\end{tabular}

There was no postoperative nausea and vomiting, choking, local anesthetic

\section{DISCUSSION}

A good control of post-operative pain following tonsillectomy resulted in decreasing morbidity and increases parent satisfaction, and there are many techniques have been tried to alleviate post-operative pain following tonsillectomy with conflicting outcomes. Glossopharyngeal nerve block results in decreasing post-operative pain after tonsillectomy and decreasing analgesic consumption (Wang et al., 2016).

As regard age and sex, there was no statistically significant difference between the studied groups, and also there was no statistically significant difference as regard heart rate, respiratory rate, and oxygen saturation. This result came in agreement with Vlok et al. (2017) who reported that there was no statistically significant difference between the studied groups as regard age, sex, heart rate, respiratory rate and oxygen saturation.

The current study demonstrated that a great benefit of glossopharyngeal nerve block in patients undergoing tonsillectomy, in which it was comparing the effect of local infiltration of bupivacaine and topical lidocaine with administration of intravenous infusion of paracetamol prior to operation, showed toxicity, hoarseness of voice, or foreign body sensation in the throat.

that there was no statistically significant difference in pain scores after $30 \mathrm{~m}, 2 \mathrm{hrs}$, and 6hrs. But there was a statistically significant difference in pain scores between three groups after 12, 18 and 24 hours. Pair-wise comparison between the groups revealed that Group B showed the statistically significant highest mean pain score. on comparing group $\mathrm{A}$ and $\mathrm{C}$, there was an increase in pain score in group $\mathrm{C}$ than group A, but without a statistically significant difference, and both showed the statistically significant lowest mean pain scores.

This result was concomitant with Yucel and $\ddot{O} z d o g ̆ a n ~(2020)$ who concluded that glossopharyngeal nerve block has a practically safe and effective form of analgesia post-operatively in different times 2hrs, 4hrs, and 6hrs. and also no need for rescue analgesia over $24 \mathrm{hrs}$. Also, it was similar to Vlok et al. (2017) where the patient had less need for analgesia. Also pain relief was of longer duration of the drug. This is explained by the phenomenon of "neuroplasticity", which proposes that pre-emptive blockade of release of nociceptive neuromediators which may contribute to the elimination of hyper-excitable state responsible for maintenance of postoperative pain. Therefore, one may speculate that the 
prolonged analgesia was attributed to successful blockade of these nociceptive impulses by the use of local anesthetic preoperatively (Ju et al., 2013).

There is a meta-analysis of seven randomized controlled trials evaluating perioperative bupivacaine infiltration for pain relief following adeno-tonsillectomy which revealed that bupivacaine infiltration in the peritonsillar region is a safe and effective during post-operative period (Vlok et al., 2017). Stelter et al. (2009) and Maryam et al. (2017) reported that post-tonsillectomy infiltration with local anesthetic is superior to preincisional infiltration.

Zhang et al. (2014), in their randomized double-blinded study, reported that pre-incisional local anesthetic infiltration in children presented for tonsillectomy significantly decreased post tonsillectomy pain, and helped in better recovery of activities.

In the current study, there was no postoperative nausea and vomiting, choking, local anesthetic toxicity, hoarseness of voice, or foreign body sensation in the throat and this result was concomitant with Yucel and Özdoğan (2020) reported that topical application of both lignocaine and bupivacaine spraying was safe and simple to be performed.

Intravenous infusion of paracetamol prior to operation also has a good analgesic effect in which pain score at $30 \mathrm{~m}, 2 \mathrm{~h}, 6 \mathrm{~h}$, and $12 \mathrm{~h}$ had no statistically significant difference, but it was founded that there was statistically Significant increase in pain score at $18 \mathrm{~h}$, and $24 \mathrm{~h}$ in comparison with group and this result was concomitant with Salonen et al. (2009) who reported that Intra venous paracetamol decreases the need to opioid doses after adeno-tonsillectomy but they combined it with ketoprofen and administer two drugs at the end of operation.

In contrast to the current finding, DahiTaleghani et al. (2011) demonstrated that there is no difference between peritonsillar infiltrations of bupivacaine compared with rectal acetaminophen suppositories in children undergoing adeno-tonsillectomy. This disagreement may be due to the high dose of paracetamol $(30 \mathrm{mg} / \mathrm{kg})$, and the use of peritonsillar infiltration technique.

\section{CONCLUSION}

The glossopharyngeal nerve block with plain bupivacaine $(0.5 \%)$ in glossotonsillar sulcus was a safe, effective, and easily applicable method for posttonsillectomy pain management, and has a significant prolonged duration of analgesia in comparison to topical lidocaine and Intravenous paracetamol. Paracetamol injection is also an effective method for pain management in tonsillectomy especially in early postoperative period with fewer side effects than lidocaine infiltration.

\section{REFERENCES}

1. Ahmed SA. and Omara AF. (2019): The Effect of Glossopharyngeal Nerve Block on Post-Tonsillectomy Pain of Children; Randomized Controlled Trial. Anesth Pain Med., 30;9(2): e90854.

2. Akkaya T, Bedirli N, Ceylan T, Matkap E, Gulen G, Elverici O, Gumus H. and Akin L. (2009): Comparison of intravenous and peritonsillar infiltration of tramadol for postoperative pain relief in children following adeno tonsillectomy. Eur J Anaesthesiol., 26(4):333-337. 
3. Dahi-Taleghani M, Mousavifard S, Tahmoureszade S. and Dabbagh A. (2011): Rectal acetaminophen versus peritonsillar infiltration of bupivacaine for postoperative analgesia after adenotonsillectomy in children. Eur Arch Otorhinolaryngol., 268:581-584.

4. Debasish G, Anindita S, Aryabrata D. and Arunabha S. (2018): Glossopharyngeal Nerve Block with Long Acting Local Anaesthetic Agent (Bupivacaine) and its Effect on Early Postoperative Period in Adult Tonsillectomy: A Prospective Study. Indian J Otolaryngol Head Neck Surg., 71(Suppl 1):390-394.

5. Inanoglu K, Ozbakis Akkurt BC, Turhanoglu S, OkuyucuS. and Akoglu E. (2009): Intra venous ketamine and local bupivacaine infiltration are effective as part of a multimodal regime for reducing posttonsillectomy pain. Med Sci Monit., 15(10):CR539-CR543.

6. Jeon EJ, Park YS, Park SS, Lee SK. and Kim DH. (2009): The effectiveness of gabapentin on post-tonsillectomy pain control. Eur Arch Otorhinolaryngol., 266(10):16051609.

7. Ju NY, Cui GX. and Gao W. (2013): Ropivacaine plus dexamethasone infiltration reduces postoperative pain after tonsillectomy and adenoidectomy. Int J Pediatr Otorhinolaryngol., 77:1881-1885.

8. Maryam H, Amin J, Sedighe V. and Vida A. (2017): Comparing the effects of peritonsillar infiltration of tramadol before and after the surgery on post-tonsillectomy pain. Eur Arch Otorhinolaryngol., 274:2521-2527.

9. Mohamed SK, Ibraheem AS. And Abdelraheem MG. (2009): Preoperative intravenous dexamethasone combined with glossopharyngeal nerve block: role in pediatric postoperative analgesia following tonsillectomy. Eur Arch Otorhinolaryngol., 266(11):1815-1819.

10. Parker D, Howe L, Unsworth V. and Hilliam R. (2009): A randomized controlled trial to compare post-operative pain in children undergoing tonsillectomy using cold steel dissection with bipolar haemostasis versus coblation technique. Clin Otolaryngol., 34(3):225-231.

11. Salonen A, Silvola J. and Kokki H. (2009): Does 1 or $2 \mathrm{~g}$ paracetamol added to ketoprofen enhance analgesia in adult tonsillectomy patients? Acta Anaesthesiol Scand., 53(9):1200-1206.

12.Stelter K, Hempel JM, Berghaus A, Andratschke M, Luebbers CW. and Hagedorn H. (2009): Application methods of local anaesthetic infiltrations for postoperative pain relief in tonsillectomy: a prospective, randomised, double-blind, clinical trial. Eur Arch Otorhinolaryngol., 266:1615-1620.

13. Stelter K, Hiller J, H, Hiller J, Hempel JM, Berghaus A, Hagedorn H, Andratschke M. and Canis M. (2010): Comparison of two different local anaesthetic infiltrations for postoperative pain relief in tonsillectomy: a prospective, randomised, double blind, clinical trial. Eur Arch Otorhinolaryngol., 267(7):112934.

14. Vlok R, Melhuish TM, Chong C, Ryan T. and White LD. (2017): Adjuncts to local anaesthetics in tonsillectomy: a systematic review and meta-analysis. J Anesth., 31:608616.

15. Wang C, Kundaria S, Fernandez-Miranda J. and Duvvuri U. (2016): A description of the anatomy of the glossopharyngeal nerve as encountered in transoral surgery. Laryngoscope, 126:2010-2015.

16. Yücel Ekici N. and Özdoğan H. (2020): Comparing local anesthetic infiltration of the peritonsillar region and glossotonsillar sulcus for post-tonsillectomy pain management. Eur Arch Otorhinolaryngol., 277(1):255-260.

17.Zhang X, Xu Y. and Li P. (2014): Effects of bupivacaine versus lidocaine infiltration on postoperative analgesia in pediatric tonsillectomy patients. Lin Chung $\mathrm{Er} \mathrm{Bi}$ Yan Hou Tou Jing Wai Ke Za Zhi, 28(03):148-150. 


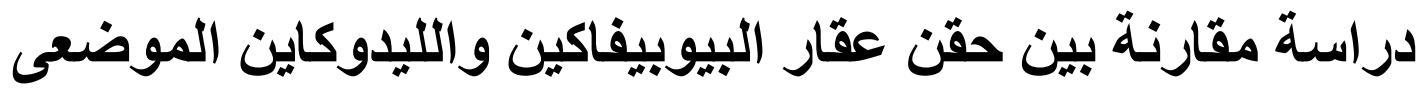

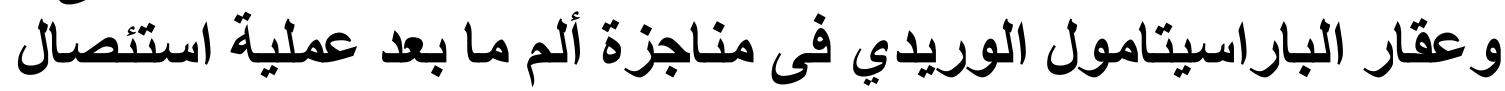
اللوزتين في الأطفال في مناخ

محمد أحمد الشرقاوى، بسرى عبدالسلام قنديل

قسمي الأنف والأذن والحنجرة و التخدير والرعاية المركزة*، كلية الطب، (القاهرة و دمياط)، جامعة الأزهر

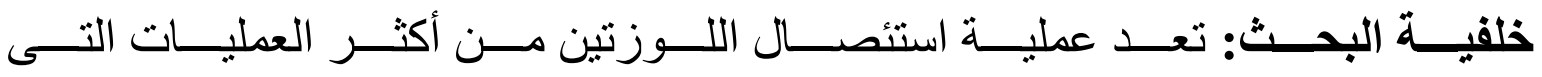

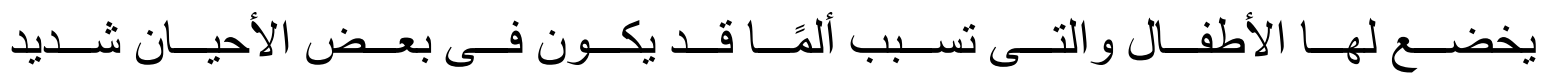

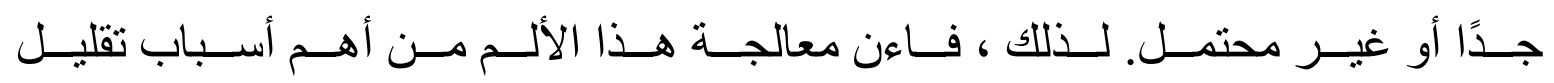

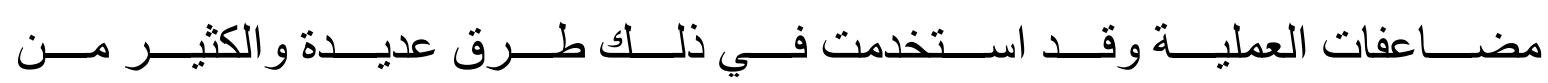
الأدوية منثل المسكنات و المخدرات سواءً كانت موضعية أو عامة.

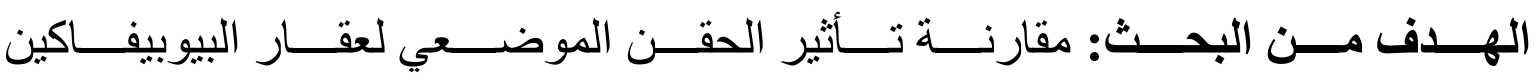

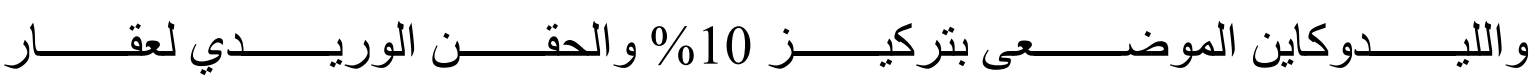

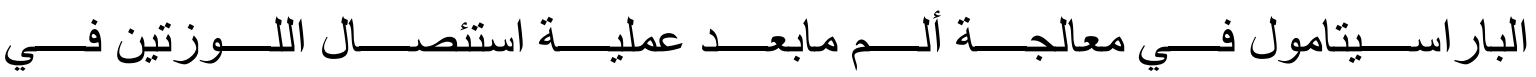

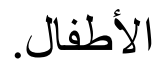

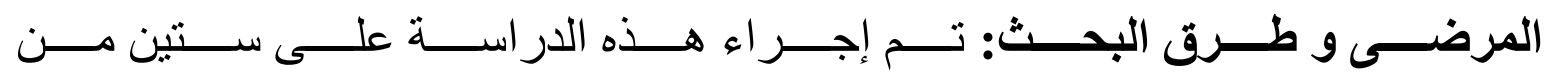

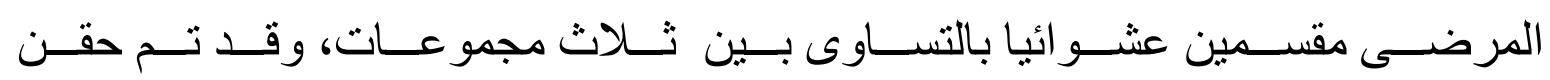

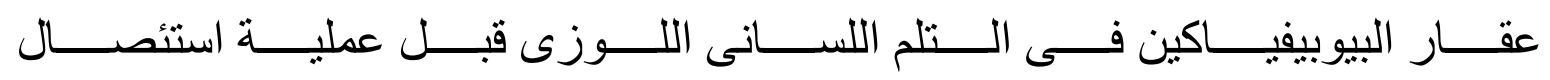

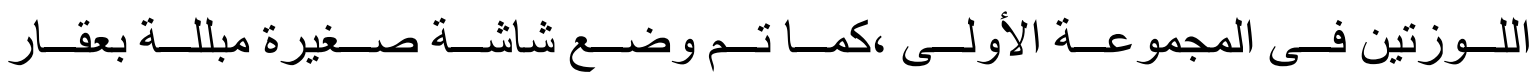

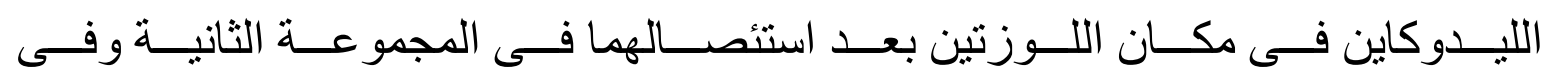

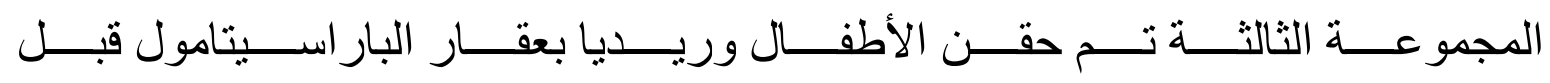

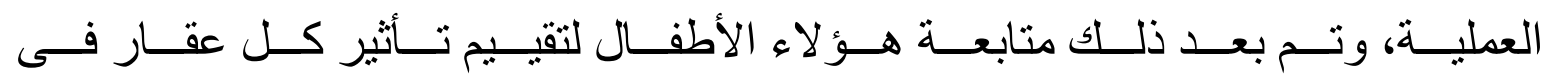
التحكم فى ألم ما بعد استنئصال اللوزتين ومدى أمانه. 
نتــائج البحـــث: لا يوجـــد فــارق إحصــائي معتبـــر بــين المجموعـــات الــنلاث

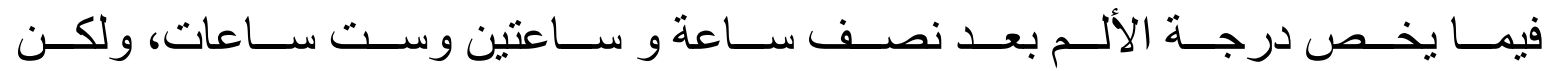

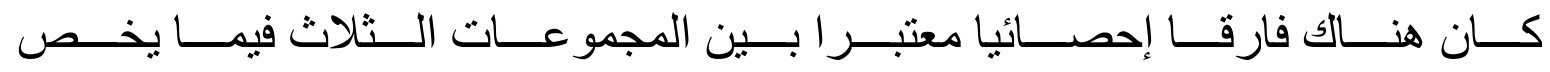

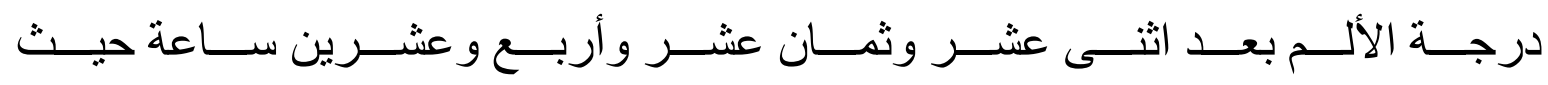

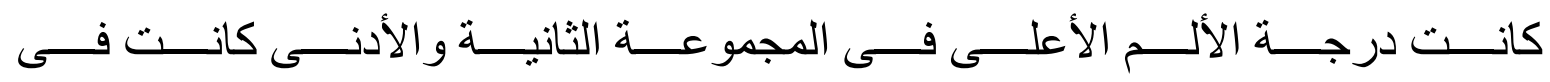
المجمو عة الأولى و الثالثة.

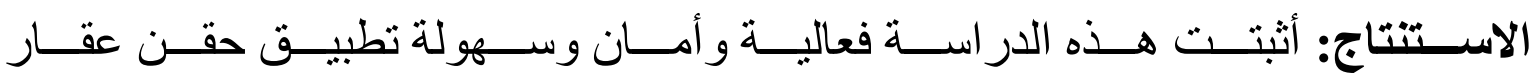

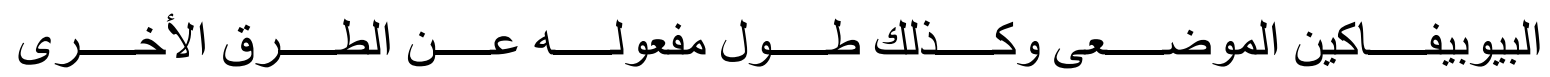
المستخدمة فى الدر اسة. 